\title{
Tooth whitening affects bond strength of adhesive systems in enamel
}

\author{
Cantídio Francisco de Lima Neto ${ }^{1}$, Carolina Batista da Silva ${ }^{1}$, \\ Marcos Aurélio Bomfim da Silva ${ }^{2}$, Rafael Pino Vitti ${ }^{3}$ \\ Carmem Lúcia de Paiva e Silva Zanta ${ }^{1}$, Josealdo Tonholo ${ }^{1}$
}

\author{
${ }^{1}$ Institute of Chemistry and Biotechnology, Federal University of Alagoas, Campus A. C. Simões, 57072-970, Maceió, \\ Alagoas, Brazil. \\ ${ }^{2}$ Faculty of Dentistry, Federal University of Alagoas, Campus A. C. Simões, 57072-970, Maceió, Alagoas, Brazil. \\ e-mail: tonholo@qui.ufal.br \\ ${ }^{3}$ Department of Prosthodontics, School of Dentistry, University of Taubaté, Rua dos Operários, 12020-270, Taubaté, São \\ Paulo, Brazil.
}

\begin{abstract}
This study presents how the tooth whitening affects the bond strength and fracture type of three distinct adhesives - a conventional, a self-etching, and a universal adhesive — in enamel. Health bovine incisors were prepared by flattening the labial surface; part of these teeth was submitted to whitening treatment with a peroxide-based product (WhiteGold Office ${ }^{\odot} 35 \%$ ). The Single Bond ${ }^{\odot}$, AdheSE ${ }^{\odot}$, or Single Bond Universal ${ }^{\odot}$ adhesive system were used to adhere a block of restorative resin to the flat surface of the teeth. Sticks measuring 10x1x1 mm were prepared and used in microtensile tests; they were also employed to examine the type of fracture. The results are analyzed with a two-way ANOVA. For both whitened and non-whitened specimens, the adhesive systems did not give statistically different bond strength values. However, the fracture shape (classified into four types) varied from a cohesive enamel type fracture for the whitened samples to a predominantly cohesive resin type fracture for the non-whitened teeth. Therefore, the whitening procedure has exerted a weakening effect on enamel even after 21 days post-treatment.
\end{abstract}

Keywords: Tooth whitening; adhesive systems; bond strength; fracture; restorative system.

\section{INTRODUCTION}

One of the commonest problems in vital and non-vital teeth is staining or darkening. Tooth whitening therapy can improve tooth appearance once application of different concentrations of hydrogen peroxide or carbamide peroxide can promote colour changes. Hydrogen peroxide is a thermally unstable chemical agent with high oxidative power; it dissociates into free radicals and reactive oxygen species such as superoxide anion $\left(\mathrm{O}_{2}^{-}\right)$, hydroxyl radical $\left(\mathrm{OH}^{\bullet}\right)$, and per-hydroxyl $\left(\mathrm{OH}_{2}^{-}\right)$[1]. These radical/anions are highly reactive against the organic specimens underlying tooth staining, the so-called chromophores, which generally consist of long-chain molecules with double bonds and aromatic rings [2].

The extensive use of adhesive materials, mainly in orthodontics and restorative dentistry, is an irreversible fate. Consequently, the lifetime durability of adhesive materials is being studied and improved year after year [3].

Elucidating the mechanism through which bleaching agents act on tooth structure is also desirable. Some authors [4] have emphasized that reactive oxygen species and free radicals react not only with chromophores but also with any available organic molecule, which supports the hypothesis that bleaching agents also react with specimens present on the surface of the resin used in restoration or on the adhesive interface. If this interaction is truly effective, it may increase the surface roughness and make it more susceptible to adhesion and proliferation of microorganisms and to staining [5].

Delfino and cols. [6] investigated how four home-bleaching peroxide-based agents (gels and solutions) affected discoloured enamel (bovine) microhardness. Carbamide peroxide gel at $16 \%$ (weight fraction, w/w) was the most effective whitening agent. However, the tested peroxides presented no difference in terms of microhardness, which evidenced that there was no attack on enamel. Didier and cols [7] studied how the 
bleaching technique has impacted the bond strength of pre-existing adhesive restorations in human tooth enamel and dentin. They used hydrogen peroxide-based whitening gels (peroxide at $7.5 \% \mathrm{w} / \mathrm{w}$ and $35 \% \mathrm{w} / \mathrm{w}$ ) on commercial composite restorations. Results suggested that the total contact time of the gel - and not the peroxide concentration - influenced the bond strength.

Another study has shown that bleaching agents do not radically modify the composition of enamel or dentin, but such agents can modify the bond strength of adhesive systems by reducing the microhardness of the dental substrate [8]. Other authors have suggested that bond strength diminishes if the restorative procedure occurs immediately after tooth whitening with peroxide because the bleaching agent temporarily affects or weakens enamel or dentin surfaces $[8,9]$. The whitening process underlies the morphological and chemical changes taking place in the substrate. The presence of residual oxygen in enamel and/or dentin causes incomplete or defective polymerization of the adhesives and composite resins employed during the restorative process.

The concentration of oxygen specimens on enamel/dentin surface tends to decay along time, which demands that some time elapses between the whitening and the restoration processes [5, 10, 11]. Authors have recommended allowing from 7 to 21 days interval between from bleaching therapy to the adhesive restoration process [9].

Suppressed calcium and phosphate contents, morphological changes in enamel prismatic layer surface, and presence of residual oxygen inside the substrate (enamel and dentin) are the main reasons for defective bonding. Residual oxygen can interfere in the adhesion of composites because it inhibit polymerization.

Therefore, this paper describes the experimental work devoted to evaluate the bond strength of three types of adhesive systems - conventional, self-conditioning, and universal - and the consequence of tooth bleaching with a $35 \%(\mathrm{w} / \mathrm{w})$ hydrogen peroxide composition, and also the character of fracture obtained in mechanical tests, in order to elucidate if any damage is caused to the resin-enamel bond by the whitening treatment.

\section{MATERIALS AND METHODS}

\subsection{Materials}

Table 1 lists the commercial brands, chemical composition and material, manufacturers, and description of the main products used in this study. Whitegold Office $35 \%$ was used as bleaching agent. Three types adhesive system were used: (a) a conventional two-step resin (Single Bond 2, 3M), (b) a self-etching bonding system (AdheSE, IvoclarVivadent), (c) a universal adhesive (Single Bond Universal, 3M).

Table 1: Materials used in this study.

\begin{tabular}{|c|c|c|}
\hline MATERIAL & COMPOSITION/DESCRIPTION* & $\begin{array}{l}\text { BATCH NUMBER AND } \\
\text { MANUFACTURER }\end{array}$ \\
\hline $\begin{array}{l}\text { Whitegold } \\
\text { Office } 35 \%\end{array}$ & $\begin{array}{l}\text { Bleaching agent. Hydrogen peroxide gel, 35\%, thickener, glycerine, sodium } \\
\text { hydroxide, Carbopol®, Deionized water, peppermint flavouring, pigments. }\end{array}$ & $\begin{array}{l}\text { 735471E; Dentsply, } \\
\text { Brazil. }\end{array}$ \\
\hline $\begin{array}{ll}\text { Filtek } & \text { z350 } \\
\text { XT }\end{array}$ & $\begin{array}{l}\text { Universal Restorative System. A combination of non-agglomerated/non- } \\
\text { aggregated } 20 \text {-nm silica, } 4 \text { to } 11 \mathrm{~nm} \text { zirconia, and aggregated zirconia/silica } \\
\text { cluster filler. The resin contains bis-GMA, UDMA, TEGDMA (to prevent } \\
\text { shrinkage), and bis-EMA(6). Color A3. }\end{array}$ & $\begin{array}{l}\text { N248065BR, 3M ESPE, } \\
\text { St.Paul, MN, EUA }\end{array}$ \\
\hline $\begin{array}{l}\text { Single Bond } \\
2\end{array}$ & $\begin{array}{l}\text { Conventional two-step bonding resin. Bisphenol A, diglycidyl ether } \\
\text { dimethacrylate (bisgma), silane-treated silica, 2-hydroxyethyl methacrylate, } \\
\text { glycerol 1,3-dimethacrylate, copolymer of acrylic and itaconic acids, water, } \\
\text { diurethanedimethacrylate, diphenyliodoniumhexafluorophosphate, andethyl } \\
\text { 4-dimethyl aminobenzoate. pH } 4.7\end{array}$ & $\begin{array}{l}\text { 1032600655; 3M ESPE, } \\
\text { St Paul, MN, EUA }\end{array}$ \\
\hline $\begin{array}{l}\text { Single Bond } \\
\text { Universal }\end{array}$ & $\begin{array}{l}\text { Universal adhesive. MHP Phosphate Monomer, dimethylacrilate resin, } \\
\text { HEMA, Vitrebond }{ }^{\text {TM }} \text { copolymer, filler, ethanol, water, initiators, silane, } \\
\text { pH=2.7 }\end{array}$ & $\begin{array}{l}\text { 1306600524. 3M ESPE, } \\
\text { St Paul, MN, EUA }\end{array}$ \\
\hline AdheSE & $\begin{array}{l}\text { Self-etching two-component adhesive system. Primer: phosphonic acid } \\
\text { acrylate, bis-acrylamide, water, initiators, and stabilizers. Bonding: } \\
\text { dimethacrylates, hydroxy ethyl methacrylate, highly dispersed silicon } \\
\text { dioxide, initiators, and stabilizers. } \mathrm{pH} 2.2\end{array}$ & $\begin{array}{l}\text { R55281 (Primer) and } \\
\text { R66900 (Adhesive); } \\
\text { IvoclarVivadent, USA }\end{array}$ \\
\hline
\end{tabular}

*Manufacturer's information 


\subsection{Methods}

\subsubsection{Teeth selection}

The original sampling consisted of 36 selected healthy cattle incisors free of cracks and fissures. The roots of all dental elements were cut about $1 \mathrm{~mm}$ below the cement-enamel junction (CEJ) with a double-sided diamond disc (KG Sorensen, Ind. Com. Ltda, Barueri, Brazil). The labial surfaces wereplanned with sandpaper consisting of 180-mesh silicon carbide (SiC) fixed over an APL-4 polisher (AROTEC, São Paulo, Brazil). The procedure was carried out under permanent water cooling.

\subsubsection{Whitening procedure.}

Eighteen of the original 36 specimens were subjected to bleaching by applying the whitening gel on the teeth surface for 45 min each one of three times, considering seven days of interval between applications (total of 21 days). After each application, the specimens were washed with distilled water, stored in polyethylene tubes containing saline solution $(0.9 \%$ in $\mathrm{NaCl})$ and placed inside an incubator oven under controlled temperature of $37^{\circ} \mathrm{C}$ for 21 days. The remaining 18 specimens were not submitted to whitening and considered to be the control group.

\subsubsection{Restoration Process.}

Based on the adhesive system, the specimens were separated into the following groups: (a)Adhesive Single Bond 2 (conventional)-unbleached and bleached enamel; (b)Adhesive AdheSE (self-etching)-unbleached and bleached enamel; (c)Single Bond Universal (Universal)-unbleached and bleached enamel. These resins were chosen because they are widely used in dental clinics (mainly in Brazil) and the brands are market leaders. The teeth submitted to bleaching were restored after a period of 21 days. The resin composite/nanoparticle blocks (Figure 1) were prepared with Filtek Z350 XT, color A3 (8x4x4 mm length, width, and height), and the desired adhesive was used on the treated tooth surface. The restorative procedure was performed according to the step-by-step incremental technique, during which every 2 -mm-thick layer was submitted to light curing for $20 \mathrm{~s}$ (LED, Radii, SDI, USA, nominal power $=1,200 \mathrm{~mW} \mathrm{~cm}^{-2}$ ).

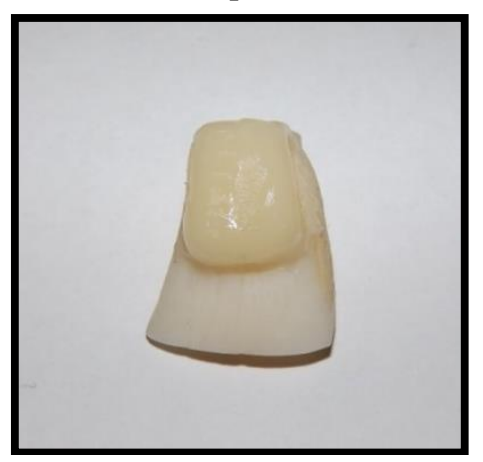

Figure 1: Resin-composite block adhered to the upper treated tooth surface.

\subsubsection{Microtensile bond strength evaluation.}

The restored specimens were fixed on acrylic plates with sticky wax and submitted to a precision metallographic machine cut (Isomet 1000, Buehler Ltd., Lake Bluff, IL, USA), which ensured precisely sectioning. The cuts were accomplished under cooling with water, in the vestibule-lingual direction, which provided $1.0 \mathrm{~mm}$ thick slices (Figure 2). After the initial procedure, new cuts were made perpendicular to the first cut, to obtain $\sim 10 \mathrm{~mm}$ longer stick-shaped samples with a square cross-sectional area of about $1 \mathrm{~mm}^{2}$.

Each one of 18 teeth furnished 10 sticks, which resulted in total of 60 samples per adhesive type. Each stick was fixed to the microtensile device with cyanoacrylate adhesive (Super Bonder, Loctite, São Paulo, Brazil), and the set (specimen + device) was attached to a universal testing machine (EZ Test, Shimadzu Co., Kyoto, Japan). A perpendicular traction force was applied to the interface at a speed of 0.5 $\mathrm{mm} \mathrm{min}^{-1}$ until the fracture was detected. 


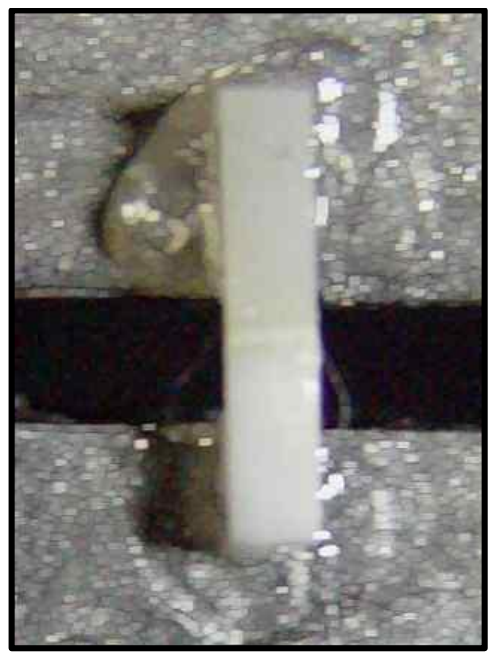

Figure 2: Sticks obtained from the teeth/restoration resin interface cuts attached to the microtensile holder.

After the sample was fractured by traction, the specimen was removed from the device, and the crosssection of the fracture plane was measured with a digital calliper (STARRET 727-6/150, São Paulo, SP, Brazil). The obtained kilogram-force (kgf) values were converted to MPa by using equation 1 .

Resistance $(\mathrm{MPa})=\left[\frac{\text { rupture force }}{\text { cross section area in } \mathrm{cm}^{2} / 100}\right] \times 0,0098$

(Eq. 1)

Fracture pattern analysis. The specimens were investigated by scanning electronic microscopy (TM3000 Hitachi High Technologies, Tokyo, Japan). This equipment had a backscattering source with two working potentials ( 5 and $15 \mathrm{kV}$ ); it was coupled to an Oxford Energy Dispersive Spectrometer. Samples were directly analyzed as prepared, with no special needs like metallization or N2 freezing. The fracture shapes were classified into four general behaviours:

Type I: Adhesive - fracture in the adhesive interface

Type II: Cohesive at resin - fracture in the resin;

Type III: Cohesive at enamel - fracture in the substrate;

Type IV: Mixed Fracture - part of the fracture in enamel and part of the fracture in the resin.

The statistical method ANOVA was used to analyze variance and also lead to a comparison between the whitening procedure and the lack of whitening procedure, among restorative materials, and among the combinations procedure + restorative material.

\section{RESULTS}

SEM images were obtained for all sticks after rupture. Figure 3A illustrates a sample of fractured stick type I (adhesive) for a whitened specimen with Single Bond 2 adhesive. Figure 3B depicts a representative fractured stick type II (cohesive at resin) for a non-whitened specimen with single Bond 2 adhesive. Figure 3C represents a sample of fractured stick type III (cohesive at enamel) with whitened Single Bond 2 adhesive. Figure 3D corresponds to a sample of fractured stick type IV (mixed) with whitened AdheSE. 
A

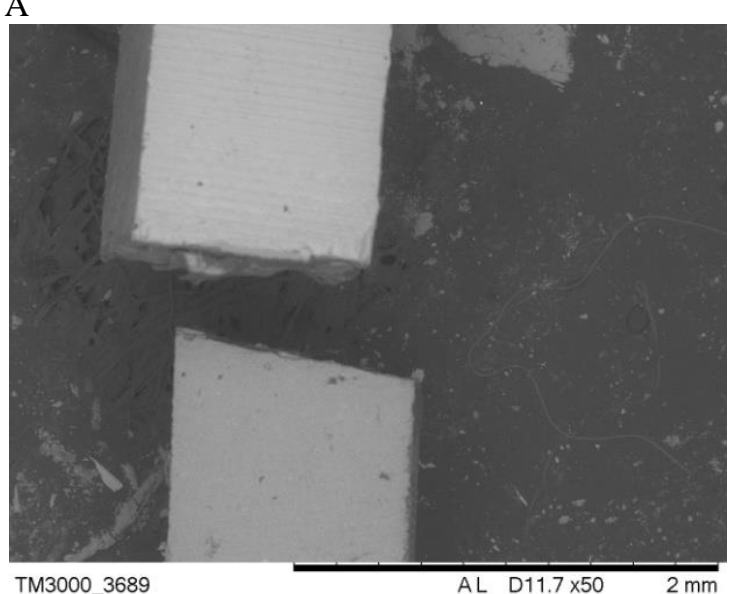

$\mathrm{C}$

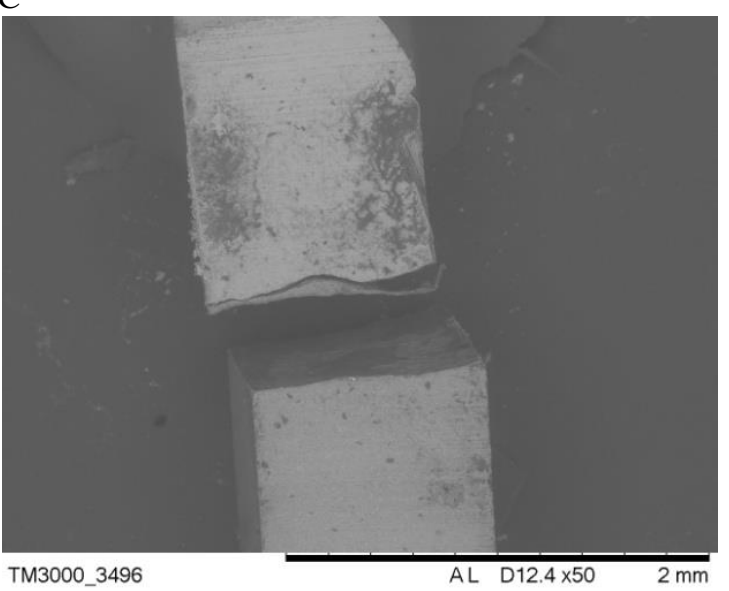

$\mathrm{B}$

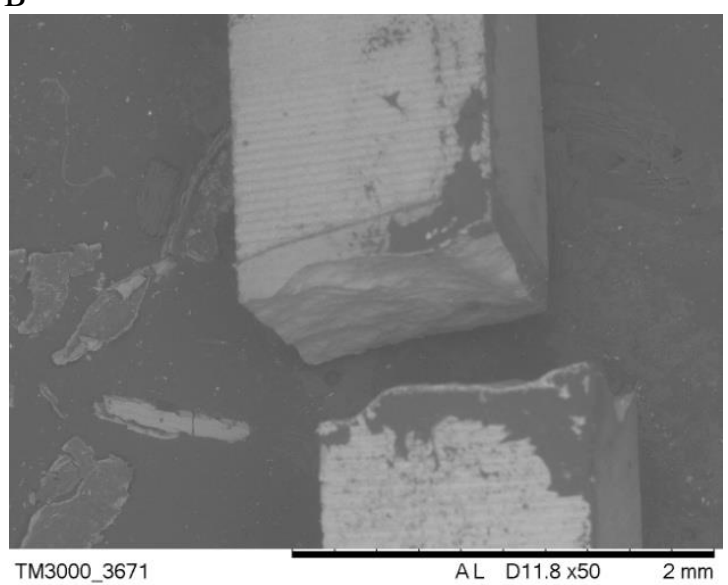

$\mathrm{D}$

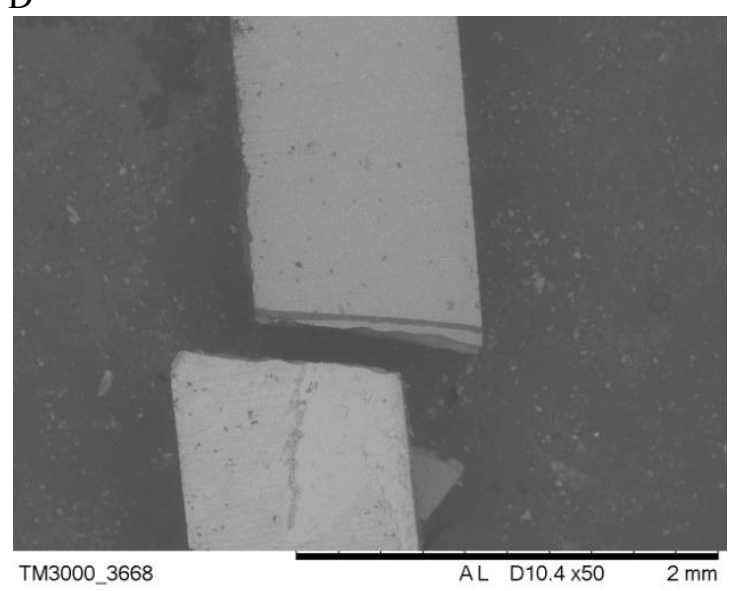

Figure 3: Classification of stick fracture: (A) type I (adhesive), (B) type II (cohesive at resin), (C) type III (cohesive at enamel) and (D) type IV (mixed).

Experimental data of microtensile tests were submitted to a two-way ANOVA analysis at a 5\% level of significance. Considering the variables whitening procedure, restorative material and combination of whitening procedure and restorative material, the bond strength values were not statistically different $(\mathrm{p}=$ 0.611408). From a statistical standpoint, the bond strength values of the teeth subjected to bleaching did not differ from the bond strength values of non-whitened teeth. Additionally, the adhesive systems used in this study did not affect the enamel/resin bond strength values.

Table 2 summarizes the mean values of bond strength with the standard deviation for the three adhesive systems and two procedures (whitened or not whitened) used herein.

Table 2: Average bond strength for sticks ( $1 \mathrm{~mm}^{2}$ cross section) of adhesive/dentin systems according to the presence or lack of whitening procedure.

\begin{tabular}{lccc}
\hline Restorative & $\begin{array}{c}\text { Whitening } \\
\text { procedure }\end{array}$ & Mean resistance (MPa) & Standard deviation (MPa) \\
\hline AdheSE & No & 41.48 & 12.71 \\
Single Bond Universal & No & 46.01 & 6.98 \\
Single Bond 2 & No & 44.66 & 10.12 \\
\hline AdheSE & Yes & 42.40 & 6.66 \\
Single Bond Universal & Yes & 36.58 & 7.06 \\
Single Bond 2 & Yes & 39.12 & 9.51 \\
\hline
\end{tabular}

Table 3 contains the percentages of fractures according to the fracture classification. The AdheSE self- 
etching system predominantly presented fractures type I (adhesive) for both bleached and unbleached enamel. Fractures type II (cohesive at resin) predominated in non-whitened specimens with Single Bond adhesive. Fractures type III and IV (cohesive and adhesive, respectively) prevailed in adhesive systems applied on teeth submitted to whitening.

Table 3: Classification of fracture type according to the adhesive system and whitening procedure.

\begin{tabular}{|c|c|c|c|c|c|}
\hline \multirow{2}{*}{$\begin{array}{l}\text { Adhesive } \\
\text { system }\end{array}$} & \multirow{2}{*}{$\begin{array}{l}\text { Whitening } \\
\text { procedure }\end{array}$} & \multicolumn{4}{|c|}{$\%$ of fractures } \\
\hline & & $\begin{array}{c}\text { Type I } \\
\text { (adhesive) }\end{array}$ & $\begin{array}{c}\text { Type II } \\
\text { (cohesive-resin) }\end{array}$ & $\begin{array}{c}\text { Type III } \\
\text { (cohesive-enamel) }\end{array}$ & $\begin{array}{l}\text { Type IV } \\
\text { (mixed) }\end{array}$ \\
\hline AdheSE & No & 50 & 20 & 0 & 30 \\
\hline Single Bond Universal & No & 20 & 40 & 10 & 30 \\
\hline Single Bond 2 & No & 10 & 60 & 5 & 25 \\
\hline AdheSE & Yes & 50 & 0 & 20 & 30 \\
\hline Single Bond Universal & Yes & 40 & 0 & 45 & 15 \\
\hline Single Bond 2 & Yes & 30 & 10 & 45 & 15 \\
\hline
\end{tabular}

\section{DISCUSSION}

The bond strength in whitened and non-whitened restored teeth containing different adhesive systems was here investigated after 21 days. Microtensile testing provides a measure of the bond strength of specimens of different shapes ("stick", "dumbbell", or "hourglass") [12]. Here, the choice of specimen shape was based on the need to measure bond strength in samples produced from a single restored tooth. Stick-shaped specimens enabled more uniform distribution of forces over a predefined joining region during microtensile tests [13].

Self-etching adhesive systems presented lower bond strength in enamel if compared to conventional adhesives [14]. The use of self-etching adhesive eliminated the acid conditioning and removal steps and dismissed control of the residual humidity. Self-etching can improve bond strength values for enamel conditioned with phosphoric acid, as in the case of conventional systems. The tests here presented followed all manufacturer's recommendations in order to not apply acid conditioning. Application of conventional, self-etching and universal adhesives in non-whitened teeth (control samples) presented no statistically different results. The enamel flattening procedure probably reduced enamel thickness, allowing acidic monomers to penetrate in the substrate $[15,16]$.

Twenty-one days after the bleaching procedure, the bond strength of the specimens, measured by microtensile tests, remained statistically unaltered as compared to the bond strength values obtained before bleaching. Borges and cols. [9] recommended using alcohol-based adhesive systems to diminish or eliminate the deleterious effects of residual oxygen on the adhesion procedure. The high volatility as well as the low viscosity of these adhesive systems should facilitate residual oxygen removal from the dental tubules, thereby improving bonding and the cure of the adhesive system. The effect exerted by alcohol is supposed the responsible to maintain the same bond strength values in non-whitened and whitened teeth in this study.

The numerical values obtained during the bond strength measurements are not enough to predict the mechanical behaviour of an adhesive system. Hence, the analysis of the surfaces of the fractured specimens has received considerable attention. Tests that allow the use of reduced cross-sectional area, such as the microtensile tests, aid complete analysis of the fractured region. Fractured surfaces contain important information regarding the integrity of the structures involved in the bond interface [17].

Enamel exposed to whitening agents can undergo mild to moderate morphological surface changes, including increased porosity, reduced hardness, loss of mineral content and modification to prismatic shape, resulting in an over-conditioned enamel appearance [18,19]. Thus, bleaching could affect the dental substrate. Application of different whitening techniques in restored teeth may represent another risk: it can weaken the bond at the tooth-restoration interface [20,21].

Although the bond strength values obtained here did not differ significantly, a different response emerged upon evaluation of the fracture pattern between whitened and non-whitened specimens. Fractures type II (cohesive at resin) and IV (mixed) predominated in non-whitened samples, whereas fractures type I (adhesive) and III (cohesive at enamel) prevailed after whitening treatment. Therefore, the adhesive interface was more effective than the cohesive strength of enamel and could support phenomena linked to changes in the composition and morphology at the enamel surface. Dominguette and cols. [22] reported that bleaching agents can reduce the microhardness of restorative materials and mineralized tissues of the teeth, thereby 
increasing microleakage in restoration resins and changing the surface morphology of enamel and dentin, ultimately affecting the bond strength of resin restorations.

Some studies have concluded that application of adhesive immediately after whitening therapy - in the presence of peroxide compounds - may impair bond strength [8,9]. Nonetheless, experimental results here presented showed that bleaching did not influence the bond strength values significantly.

In fact, changes in enamel morphology and chemical composition have been reported as one reason for reduced bond strength in restorations after whitening $[5,10,23]$ recommended waiting between seven and twenty-one days to apply adhesive restorations after bleaching.

Even though the adhesive processes were applied 21 days after bleaching, the whitening procedure clearly changed the fracture pattern in the substrate. Therefore, the 21 days of waiting might not be enough for minerals on the enamel surface to recover completely or at least to return to a condition close to the original condition. This may bring consequences for the mechanical behaviour of the enamel surface. Our results probably stem from the bond strength weakening effect elicited by changes in fracture type; they suggest the substrate becomes more fragile after bleaching. Restoration lifetime and bond strength maintenance have motivated companies and dentists to conduct research into this issue.

\section{CONCLUSION}

This paper presented the influence of the conventional bleaching/whitening teeth treatment over the bond junction resin-enamel for three different types of resin: conventional, a self-etching, and a universal adhesive, using mechanical bond strengths need to fracture the sticks samples and the classification of theses fracture types. The bond strength results of the tested adhesive systems showed to be very similar for both the whitened and non-whitened teeth, with no statistical difference, leading to reinforce the hypothesis the whitening therapy did not affect the studied resins, although bonding procedure was carried out 21 days after. On the other hand, the analysis of fracture type revealed the affects in morphology of the enamel resulting in change of fracture type, where cohesive at resin and mixed types prevailed in non-whitened samples. Adhesive and cohesive at enamel types prevailed in samples submitted to whitening treatment.

\section{ACKNOWLEDGEMENTS}

The authors acknowledge FAPEAL, CNPq, FINEP, and CAPES for financial support and fellowships.

\section{BIBLIOGRAPHY}

[1] KAWAMOTO K, TSUJIMOTO Y. "Effect of the hydroxyl radical and hydrogen peroxide on tooth bleaching", J Endod , v.30, pp. 45-50, 2004.

[2] MCCRACKEN, M.S., HAYWOOD, V.B. "Effects of 10\% carbamide peroxide on the surface hardness of enamel", Quintessence Int ., v.26, pp. 21-24, 1995.

[3] NICHOLSON, J.W. "Adhesive dental materials and their durability", International Journal of Adhesion \& Adhesives, v.20, pp.11-16, 2000.

[4] MARKOVIC, L., JORDAN, R.A., LAKOTA, N., et al., "Micromorphology of enamel surface after vital tooth bleaching", J Endod., v.33, n.5, pp. 607-10, 2007.

[5] ATTIN, T., HANNIG, C., WIEGAND, A., et al., "Effect of bleaching on restorative materials and restorations - a systematic review", Dent Mater, v. 20, n.9, pp. 852- 861, 2004.

[6] DELFINO, C.S., CHINELATTI, M.A, CARRASCO-GUERISOLI, L.D., et al., "Home belaching agents in discoloured teeth and influence on enamel microhardness", J Appl Oral Sci., v.17, n.4, pp.284-288, 2009.

[7] DIDIER, V.F, BATISTA, A.U.D, MONTENEGRO, R.V, et al., "Influence of hydrogen peroxide-based bleaching agents on the bond strength of resin-enamel/dentin interfaces", International Journal of Adhesion \& Adhesives, v.47, pp.141-145, 2013.

[8] NOUR EL-DIN, A.K., MILLER, B.H, GRIGGS, J.A., et al., "Immediate bonding to bleached enamel", Oper Dent., v.31, n.1, pp. 106-114, 2006.

[9] BORGES, A.B, RODRIGUES, J.R, BORGES, A.L.S., et al., "The influence of bleaching agents on enamel bonding strength of a composite resin according to the storage time", Rev Odontol UNESP, v.36, n. 1, pp.77-83, 2007. 
[10] AMARAL, C., JORGE, A., VELOSO, K., et al., "The effect of in office in combination intracoronal bleaching on enamel and dentin bond strength and dentin morphology", J Contemp Dent Pract., v.9, n.5, pp.2-8, 2008.

[11] CADENARO, M, ANTONIOLli, F, SAURO, S., et al., "Degree of conversion and permeability of dental adhesives", Eur J Oral Sci ., v.113, n.6, pp.525-530, 2005.

[12] SCHERRER, S.S, CESAR, P.F., SWAIN, M.V. "Direct comparasion of the bond strength results of the different test methods: a critical literature review”, Dent Mater., v.26, n.2, pp.78-93, 2010.

[13] PASHLEY, D.H, CARVALHO, R.M, SANO, H., et al., "The microtensile bond test: a review", J Adhes Dent., v.1, n.4, pp.299-309, 1999.

[14] CARVALHO, A.P.M.C., TURBINO, M.L. "Can previous acid etching increase the bond strength of a self-etching primer adhesive to enamel?", Braz Oral Res., v.23, n.2, pp.169-74, 2009.

[15] CHERSONI, S, SUPPA, P, GRANDINI, S, et al., "In vivo and in vitro permeability of one-step selfetch adhesives", J Dent Res., v.83, n.6, pp.459-64, 2004.

[16] VAN LANDUYT, M., PEUMANS, M., et al., "Lambrechts P, Meerbeek B. Extension of a one-step self-etch adhesive into a multi-step adhesive", Dent Mater., v.22, n.6, pp.533-44, 2006.

[17] VAN MEERBEEK B, VARGAS M, INOUE S, et al., "Microscopy investigations. Techniques, results, limitations", Am J Dent , v.13, 5 Spec, 2000.

[18] ATTIN, T., BETKE, H., SCHIPPAN, F., et al., "Potential of fluoridated carbamide peroxide gels to support post-bleaching enamel re-hardening”, J Dent., v.35, n.9, pp. 755-759, 2007.

[19] PHAN X, AKYALCIN S, WILTSHIRE W, et al., "Effect of tooth bleaching on shear bond strength of a fluoride-releasing sealant”, Angle Orthod., v.82, n.3, pp.546-551, 2012.

[20] DURNERA J, STOJANOVIC M, URCANA E, et al., "Effect of hydrogen peroxide on the threedimensional polymer network in composites”, Dent Mater, v.27, n.6, pp.573-580, 2011.

[21] OLIVEIRA, M.T, ANDRADE, M.A.C., MICHELS, M. "Oxygen release, microleakage and shear bond strength of composite restorations after home dental bleaching”, Rev Odonto Cienc., v.26, n.1, pp. 45-49, 2011.

[22] DOMINGUETTE, A.A.S, RIBEIRO, J.G., MOYSÉS, M.R., et al., "Avaliação da resistência adesiva de resina composta em esmalte de dentes clareados em função de sistemas adesivos", Revista Univ Vale do Rio Verde, v.10, n.1, pp. 396-402, 2012.

[23] ARAUJO, L.S.N., LEME, A.A., AGUIAR, T.R., et al., "Effect of solvent volatilization temperature on the stiffness of adhesive systems", Dent Mat., v.29, Sup.1, pp.e66-e67, 2013. 